\title{
Enhancing Information Systems Students' Soft Skill - a Case Study
}

\author{
Aharon Yadin \\ Department of Management Information Systems, The max Stern Yezreel Valley College (YVC), \\ Yezreel Valley, Israel \\ Email: yaharony@yvc.ac.il
}

\begin{abstract}
Information Systems (IS) curricula should provide students with both technical and non-technical (soft) skills. The technical aspects are covered by various courses. However, soft skills like teamwork, interpersonal communication, presentation delivery, and others are hardly covered. Employers, who consider both technical and soft skills to be equally important, search for professional Information Systems employees possessing both sets of skills. These employers often complain that finding an IS graduate with both types of skills is quite difficult. The IS 2010 Model Curriculum refers to both types of skills, considering them an essential part of the graduate knowledge base. However, in many cases the soft skills are not sufficiently addressed, and even if they are, it is not necessarily in the context of software development projects. The Systems Analysis and Design (SAD) course provides an important foundation for the IS profession. This is especially true due to the emerging role of the programmer-analyst who is responsible not only for programming but also for some analysis work. In order to strengthen the soft skills in the context of system analysis and design, we suggest a workshop structure emphasizing these soft skills while students analyze and design a complete information system. Our SAD workshop includes some face to face lectures and teambased collaborations. The students undertake many online activities, including teamwork, interviews with simulated clients, team-based peer reviews, presentation delivery, and so forth. The workshop employs a grade difference calculation mechanism that revealed, along with the students' reflections, that the workshop structure enhanced the students' ability to cope with the workshop assignments while strengthening their soft skills and preparing them for their future analysis and design challenges.
\end{abstract}

Index Terms - Systems Analysis and Design, Soft Skills, Peer Review, Practical Learning

\section{INTRODUCTION}

This paper describes an instructional module which is based on a System Analysis and Design (SAD) workshop taught as part of the Management Information Systems (MIS) program. SAD is one of the core courses in almost every MIS program (for undergraduate students) in which students learn how to turn clients' needs into a qualitative information system through ordered stages that follow the System Development Life Cycle (SDLC). In this instructional module the students practice and enhance their technical and non-technical skills while planning, analyzing and designing an information system. However, special emphasis was given to the non-technical skills in designing the workshop's structure. Such a workshop structure can provide the students with the necessary skills in the right context and prepare them for real-world challenges.

The paper includes a literature review regarding the importance of soft skills for IS graduates, a brief description of the SAD workshop that was used for enhancing the soft skills, the study performed and the results obtained followed by a discussion.

\section{LITERATURE REVIEW}

Project management, one of the MIS graduate capabilities, has emerged as a methodology for managing the various activities required to ensure the successful achievement of a project's goals [1]. The research surrounding project management continues to grow as projects become more complex, spanning several organizational units and requiring a vast array of technical capabilities. By their nature software-based systems are complex [2] due to their intangibility and the requirement for several levels of abstraction. Abstraction is a fundamental concept of computer science (CS), software engineering (SE), and information systems (IS) that provides the ability to examine various issues related to the project at different levels of detail. Nevertheless, using abstraction for better understanding the systems' requirements also increases the complexity since abstraction is not an easy topic to learn [2]. However, in spite of rapid advances in tools, technologies, and methodologies, the success of project managers who orchestrate their teams' work into a coherent effort to get things done cannot be achieved only through the use of technical skills. The ability to influence, assign, oversee, delegate, supervise, negotiate, and manage is crucial for success. Excellent interpersonal and "soft" skills are essential prerequisites for a successful manager. Sampson (p. 41) [3] writes, "The skills required for project management are now often divided 50/50 into traditional 
'hard' skills, such as risk management and scheduling, and 'soft', people oriented skills, such as interpersonal communication."

However, as mandatory modern competencies, soft skills are not confined only to project managers or information systems professionals who aim to become future managers. Many of the software attributes, such as complexity, intangibility and abstraction apply to the professional people and not only to their managers. Dealing successfully with these attributes increases the importance of non-technical skills such as communication among IS, non-managers, professionals as well. In an article dated back to 1981, Peter Kean analyzes the long term changes in organizations in relation to IS and defines "new" skills that must be developed among the systems staff, the "Hybrid" skills [4]. He stated that for successful implementation of IS, the professional people cannot dismiss organizational and political issues as irrelevant. In 1996 Earl, Edwards and Feeny [5], defined the Hybrid employee as "a person with strong technical skills and adequate business knowledge, or vice versa." [5].The importance of soft skills for IS graduates' future employment was addressed by numerous surveys. Although many of these surveys have been aimed at analyzing future technological trends to help prepare students for the new market demands, they have also revealed the need for soft skills as well. In an early study [6] of the gap between the skills taught by academia and the skills required by businesses, it was revealed that while the academic emphasis is placed mainly on the technical aspects, the profession's requirements are more toward the business and human orientation. Two years later, another study [7] supported these conclusions when it found that there was a misalignment between the IS curricula in academia and business needs. Further studies [8], [9], [10] were consistent in finding that employers rate the non-technical skills higher than the technical ones. The suggested explanation was that the non-technical skills apply to all the IS positions, while the technical skills are, in many cases, relevant only to a specific role. In 2005 Zielinski (p.22) [11] wrote that, "If you had asked projectmanagement gurus five years ago to name the most important competencies project managers should have, most would have said technical skills. Today they'd be more inclined to place communications or negotiations acumen at the top of their lists." This understanding regarding the relative importance of soft skills currently exists not only for project managers, but for the whole IS professional community [12], [13].

The IS competencies required by business and industry include both technical and non-technical skills. Technical skills refer to capabilities related to professional methodologies for requirements elicitation and analysis, system design, human computer interface design, software validation and verification, software quality, and software development and implementation. Non-technical skills or soft skills refer to people-related activities such as communication, teamwork, collaboration, planning, subject leading, presentation delivery, writing skills, and work assessment.

Many employers consider both the technical and nontechnical skills to be equally important, and search for professional employees possessing both types of skills [14], [15]. In addition, graduate students with good soft skills are often quickly placed on mission critical project teams [16]. Moreover, industry leaders point out that when they recruit new graduates and have to choose between a candidate with highly developed technical qualities and a candidate with highly developed interpersonal traits, the latter wins most of the time [17]. This supports previous findings [8], [9], [10] that employers regard the non-technical (or soft) skills more highly than the technical ones when promoting employees to more important roles with a higher level of responsibility. This of course applies to managers as well as to professional non-manager employees.

These changing trends regarding the relative importance of soft skills were addressed by the special task force that defined the IS curriculum. The IS 2010 curriculum guidelines for Undergraduate Degree Programs in Information Systems [18] as well as the previous IS 2002 Model Curriculum [19] refer to both technical and non-technical skills, and consider them both to be essential competencies. The IS 2002 defined four high level competencies graduates should possess: (1) Business Fundamentals; (2) Technology; (3) Analytical and Critical Thinking; and (4) Interpersonal, Communication, and Team Skills. Only by combining all four competencies, will the graduate be able to produce successful IS, defined by this model curriculum as "Technology-Enabled Business Development."

The IS 2010 Model Curriculum used a different high level approach and defined three pillars of knowledge and skills that IS graduates should possess: (1) Information Systems Knowledge and Skills, which includes all the relevant competencies related to the IS discipline; (2) Fundamental Knowledge and Skills, which are not specific to the IS discipline but shared with many other disciplines and comprise mainly soft skills such as "leadership and collaboration, communication and analytical and critical thinking"; and, (3) Domain Fundamentals, which refer to knowledge related "to the domain to which a specific Information System program applies computing." The guidelines presented in the IS 2010 Model Curriculum specifically address the Fundamental Knowledge and Skills, and they state that while these competencies are not unique to the IS profession, more emphasis should be placed on enhancing these skills among graduates.

Technical skills are usually learned through a series of courses that teach the student how to design and develop efficient computer programs and how to build systems that address clients' needs. But although the soft skills, or the Fundamental Knowledge and Skills in IS 2010 terms, are required they are not explicitly defined, so instructors and scholars have tried suggesting ways of incorporating 
these skills into the ordinary courses. Many papers in recent years have suggested new approaches to teaching soft skills or enhancing students' competencies in this area; most of them deal with teams and capstone projects in IS programs [20], [21], [22], [17], [23], [24] and address mainly communication and team-based skills.

\section{SOFT SKILLS REQUIRED}

Industry uses many synonyms for non-technical skills, such as "soft skills," "people skills," "emotional skills," and so on. Whatever names are used, the category of soft skills refers to the cluster of personality traits and attitudes that drives one's behavior [25]. The IS 2002 and IS 2010 define some of the categories of non-technical competencies that are required; for example, graduates need "Strong analytical and critical thinking skills to thrive in a competitive global environment," or they have to "exhibit strong ethical principles and have good interpersonal communication and team skills." [18]. Other researchers and scholars relate to listening skills as one of the "most neglected aspect of communication" [26]. To better prepare graduates for real life tasks, various surveys have been conducted. Some employers find that new graduates "lack key inter-personal skills" [27]. Cappel [28] suggests that the most important soft skills, applying to all IS jobs, are oral and written communication, problem solving, and the ability to learn. Faheem [29] reviewed 250 job descriptions for software developers and concluded that nine soft skills are required: (1) communication; (2) interpersonal; (3) analytical and problem-solving; (4) organizational; (5) fast learning; (6) team playing; (7) ability to work independently; (8) innovative and creative; and (9) open and adaptive to changes. This survey was conducted in several countries and although there were significant differences between North America and the rest of the world regarding interpersonal, analytical, organizational, and open to changes skills, the most important set of skills was communication. This may be explained by the open and global nature of software and the fact that many software development projects are performed offshore or partially outsourced. These globalized patterns of work concerning product development, collaboration, and service provision are typical of the twenty-first century and require special emphasis on communication skills.

\section{THE SYSTEMS ANALYSIS AND DESIGN WORKSHOP}

This study was performed as part of the SAD workshop. The workshop structure is explained in this section, including the participating students. In addition, information regarding the various assignments given during the workshop and the timetable and grading scheme are also presented.

\section{A. About the Study Participants}

The study was performed within the SAD workshop, which is a mandatory course taken during the third (and last) year of the studies, awarding 3 credit points to the participants. The workshop objectives are to assimilate the systems analysis and design principles, and prepare the students for their final project and for the real world challenges they will face. At this stage, the students have a good understanding of the technical knowledge areas required for the workshop (software engineering, software modeling, UML usage, etc.); however, most of them still lack the non-technical competencies required by both the Model Curriculum and the marketplace. For this reason, the workshop focuses on practical "hands-on" experience and on team-based activities aimed at enhancing the students' soft skills in parallel to the workshop's technical objectives.

\section{B. The Course Structure}

During the first lecture, the students were instructed to form teams. Usually there were three students in a team. Each team received and worked on its own case study. The case study included a general description of a virtual customer and a business case. The students had to study their story, address the problems presented in the business case, and suggest ways (and a software-based system) to solve these problems in order meet the customer's requirements. These goals were defined in a generic way in the case study, so students had to elaborate and demonstrate their creative thinking. The workshop structure was based on incremental assignments that followed the software development life cycle. The main reason for using a different business case for each team was to allow for a peer review process. Each document was prepared by one team and evaluated by another. By using different business cases the evaluating team has to spend more time on learning and evaluating the other business cases. For each assignment the students had 2-3 weeks in which they worked first by themselves, and later together. They used various online collaborative tools of their choice and if necessary consulted the instructor (via email, the workshop web site, and personal meetings). Since the students were on a tight schedule, they had to learn to use various collaborative tools (such as Live Workspace, a messaging service, etc.), since one of the aims of the workshop was to address this type of collaboration. The team-based learning employed in this workshop does not imply that only actual face to face meetings took place, but rather the students combined the use of the appropriate technologies for achieving this goal. The workshop requirements included two types of deliverable (assignments): (1) team assignments; and (2) personal assignments.

\section{The Workshop Timeline}

The workshop structure was quite complicated and the amount of work required was significant — this is the one of the reasons behind having teams of three students. The workshop employed a LEGO-like approach of modular assignments that required a strict schedule. Each one of the team assignments was reviewed, evaluated, and graded twice, firstly by the instructor and secondly by another team. In order to condense all the assignments 
into a standard 13 week semester, these activities were performed in parallel. After an assignment was submitted it was distributed to a different team for review and evaluation. Each team had to review, assess, and grade the assignments they received in parallel and start preparing their next document. The schedule provided assurance that the feedback (both from the instructor and from the evaluating team) would be available at least one full week prior to the submission date for the next assignments, so it could be taken into consideration. To stress the user-centric approach, the workshop included two face to face simulation sessions as follows: (1) a requirements gathering session: a one hour meeting for each team in which the students meet the "customer" (in this case the instructor assumed the role of the customer); and (2) a user meeting: that is half an hour for each team in which the students meet the user community to discuss various design issues and present the solution to be developed. The user community was represented by the whole class.

The activities shown in Table 1 provide a better understanding the workshop structure and outline of the class and students' activities along with the semester timeline (a standard 13 weeks).

TABLE I. WORKSHOP ACTIVITIES AND TIMELINE

\begin{tabular}{|c|c|c|}
\hline Week & Class Activity & Students Activity \\
\hline 1 & $\begin{array}{l}\text { Lecture (introduction, } \\
\text { the business environment, } \\
\text { project initiation and } \\
\text { management) }\end{array}$ & $\begin{array}{l}\text { Form team; nominate team leader, who is responsible for managing } \\
\text { the workload among the team members; produce a story and start } \\
\text { understanding the "customer" and the problems presented. }\end{array}$ \\
\hline 2 & $\begin{array}{l}\text { Lecture (projects } \\
\text { identification and } \\
\text { selection, requirements } \\
\text { engineering) }\end{array}$ & $\begin{array}{l}\text { Initiate and plan the project; work on project initiation and planning } \\
\text { document (first assignment); look for outside help (instructor) for } \\
\text { addressing the problems; apply learned principles to the story } \\
\text { situation. }\end{array}$ \\
\hline 3 & $\begin{array}{l}\text { Lecture (software } \\
\text { modeling - process } \\
\text { model, logical model) }\end{array}$ & $\begin{array}{l}\text { Start requirements analysis; discuss and finalize first assignment; } \\
\text { start working on an agreed list of questions and issues to be addressed. }\end{array}$ \\
\hline 4 & $\begin{array}{c}\text { Lecture (software } \\
\text { modeling — data model) }\end{array}$ & $\begin{array}{l}\text { Prepare the user requirements gathering simulation (part 1); submit } \\
\text { first assignment and prepare a document for review and grading; } \\
\text { conduct meetings (or virtual meetings) to mutually discuss the } \\
\text { reviewed document; prepare and agree feedback and grade. }\end{array}$ \\
\hline 5 & $\begin{array}{l}\text { User requirements } \\
\text { gathering simulation }\end{array}$ & $\begin{array}{l}\text { Submit document for review and evaluation of grade; analyze the } \\
\text { requirements and work on the analysis document (second assignment); } \\
\text { conduct face to face customer interviews for refining requirements. }\end{array}$ \\
\hline 6 & $\begin{array}{l}\text { System modeling class } \\
\text { (hands-on laboratory) }\end{array}$ & $\begin{array}{l}\text { Finalize second assignment by addressing all relevant information; } \\
\text { review comments and suggestions. }\end{array}$ \\
\hline 7 & $\begin{array}{l}\text { System modeling class } \\
\text { (hands-on laboratory) }\end{array}$ & $\begin{array}{l}\text { Submit second assignment and prepare a document for review and } \\
\text { grading; conduct meetings (or virtual meetings) to mutually discuss } \\
\text { the reviewed document; prepare and agree upon feedback and grade. }\end{array}$ \\
\hline 8 & $\begin{array}{l}\text { User meetings } \\
\text { simulation (design } \\
\text { requirements) }\end{array}$ & $\begin{array}{l}\text { Submit document for review and evaluation of grade; attend the } \\
\text { user meetings for discussing various design issues; work on the design } \\
\text { document (third assignment). }\end{array}$ \\
\hline 9 & $\begin{array}{l}\text { Lecture (project } \\
\text { implementation) }\end{array}$ & $\begin{array}{ccc}\text { Finalize third assignment (address review comments and } \\
\text { suggestions); start working on customer presentation. }\end{array}$ \\
\hline 10 & Presentations & $\begin{array}{l}\text { Submit third assignment; start working on the implementation } \\
\text { document (fourth assignment); evaluate presentations and prepare a } \\
\text { document for review and grading; conduct face to face or digital } \\
\text { customer interviews for refining requirements. }\end{array}$ \\
\hline 11 & Presentations & $\begin{array}{l}\text { Finalize fourth assignment by addressing review comments and } \\
\text { suggestions; evaluate presentations. }\end{array}$ \\
\hline 12 & Presentations & $\begin{array}{l}\text { Submit fourth assignment and prepare a document for review and } \\
\text { grading; evaluate presentations; conduct face to face or digital } \\
\text { customer interviews for refining requirements. }\end{array}$ \\
\hline 13 & Presentations & $\begin{array}{l}\text { Evaluate presentations; submit document for review and grade } \\
\text { evaluation; prepare and submit personal report. }\end{array}$ \\
\hline
\end{tabular}




\section{Team Assignments}

Three types of team assignments were included in the workshop: (1) compiling four documents; (2) reviewing four documents (which were prepared by other teams); and (3) preparing and delivering a class presentation.

Compiling the documents -- The four documents to be compiled and submitted during the workshop were as follows: (1) project initiation and planning; (2) system analysis; (3) system design; and (4) system implementation document. The documents represented the common perspective of each team on the issue. In preparing a document, each team member had to follow a predefined template that was posted on the workshop's web site. Only after each team member had worked on the document individually did the team meet (either face to face or by using a collaborative tool) to discuss all issues. This consensus meeting was required for achieving a common and unified solution. This unified solution was later translated into the document submitted by the team. A consistent grading guideline was provided for each template. These guidelines outlined the relative grade assigned to each item in the document (or its relative importance). This was done mainly in order to help the students define the amount of time they ought to spend on each item. During document preparation, the students were expected to consider the various issues related to their project and to take into account the relative weight assigned to each section.

Reviewing documents -- Each document produced was reviewed and assessed by another team, as well as by the instructor. The review was based on the document template and the grading guidelines that were provided. Each team decided on the review process they carried out, and whether it should be performed in a collaborative session or by the individual students in the team. Since the evaluation affected the grade, all students were usually engaged in the process.

Presentations -- The presentations provided a summary of all the teamwork and all the team members had to participate. The presentations were defined as technical selling presentations, and the teams had to convince the customer that they understood the problems and were able to provide suitable solutions. The grade for each presentation was awarded on a team basis. This was done to stress the collective aspect of the work and to raise each member's personal accountability. The presentations followed a predefined template and started with a brief description of the virtual customer, the business case, and associated problems. The main part of the presentation was a description of the information system proposed as a solution. In addition, the presentations covered the risks associated with the project, the expected benefits, the timeframe, and preliminary cost estimates. Thirty minutes were allocated for each presentation, which included time for answering questions raised by the customer (the students and the instructor).

\section{E. Personal Assignments}

The personal assignments consisted of two parts: (1) a review, assessment, and evaluation of the presentations given by all other teams; and (2) the preparation of a personal report reflecting the student's thoughts about the work performed and the workshop itself.

Evaluating presentations -- The evaluation form, available on the workshop web site, provided guidelines for the presentation. This evaluation form defined the relative grade assigned to each of the issues related to the presentations, including the technical issues, appearance (font size and colors), and timeframe. Every student assessed the presentation as if he or she were the customer. The main questions addressed the proposed solution and whether it convincingly solved the problems identified. The evaluation related to the team as a whole and the evaluating student had to provide an average of the team members' performance. Presentation skills (as well as technical skills) varied among the team members; however, it was their responsibility to rehearse as much as was necessary so that the team presentation achieved the required outcome.

Personal report -- Each student prepared a personal report which consisted of several components: (1) feedback on the proportional contribution of each of the other team members: this feedback was used to assess the distribution of work among the team members, taking into account the team member's point of view (it also provided sociometric data, which was interesting in itself, but that is beyond the scope of this paper); (2) a reflection on the work done by the team and by the student as part of the team, with special emphasis on the new experience gained by the individual student; and (3) a reflection on the workshop as a whole, covering benefits as well as suggested improvements.

\section{F. The Workshop Grading Scheme}

Both the assessments and grading of each document (by the instructor and by another team) were performed based on the common grading guidelines available on the workshop web site. The review process for the documents demanded significant effort dedicated to the evaluation of the work. The estimated time for each document evaluation was about 60-90 minutes on average. The assignment grade was calculated using a weighted average, in which the instructor's grade weighting was $80 \%$, while the team's grade weighting was $20 \%$. However, this average was calculated only if the difference between the two grades was 15 points or less. If the difference was more than 15 points, the students' evaluation grade was not taken into account in determining the submitting team's grade. The use of a grading template served to enforce habits of the precise and thorough analysis of documents, and to eliminate cases in which a team tried to improve (or spoil) the grades of a fellow team. 
In addition to the assignment grade, each team was also graded for their review and evaluation of the other team's documents. This grade was calculated on the basis of the difference between the instructor's grade and the team's grade, and on the quality of the judgment processes expressed by the students and the feedback they provided in their review. The presentation prepared by the team was graded as well and this grade was mainly based on peer review performed by the other students.

\section{THE STUDY}

In their final year and as part of their final project IS students are required to analyze, design, and implement a complete information system by themselves (working in teams of two students). This final project simulates and prepares the students for the future real-world challenges. Although the project is supervised by educators, most supervisors do not give special attention to non-technical skills, grading only the technical aspects of the products. Since the supervisors do not take part in the development process, nor participate in meetings with clients, no feedback is given to the students regarding their work routine. Some IS programs include courses dedicated to communication, inter-personal relationships, project management, or other non-technical skills, but in most cases the students do not practice these skills in the context of system development. Surprising as it seems, many IS graduates, especially in the past five years, have never participated in peer reviews, assessed colleagues' work products, delivered a presentation based on their work, or even learned good teamwork methods during their studies. As a result, many IS graduates lack the essential skills required by industry, and they have to acquire these skills through work experience. For this reason, IS programs such as the IS 2010 Model Curriculum suggest new approaches to the teaching of these soft skills along with technical skills, providing students with the knowledge and experience required for this profession.

The SAD workshop has predefined objectives, which mainly relate to enhancing the students' competencies regarding the methodologies and the processes of analyzing and designing a new Information System. However, because many scholars have drawn attention to the importance of soft skills, as defined in the Model Curriculum, and in order to better prepare the students for open society with its emerging opportunities, a special workshop structure was defined. This structure was intended to enhance the soft skills required through a set of activities related to the course. However, to assess the change in the students' perception of the importance of soft skills, a single question questionnaire was used. As part of the first lecture, a short discussion about technical and non-technical competencies was conducted, followed by the questionnaire. In the question, the students were asked to rate the relative importance of technical and nontechnical skills to the overall development process. The same questionnaire was used during the last lecture as part of the personal report each student had to compile. The differences between the two questionnaires were evaluated. The study was performed during the 2012 academic year and there were 32 students who were divided into 11 teams (10 teams of three students and one team of two students).

\section{RESUlts AND CONCLUSIONS}

At the end of the workshop, and after analyzing the differences between the two questionnaires, it was clear that the students had understood and assimilated some of the importance of the soft skills. At the time of the first lecture, the average students' perception was that nontechnical skills account for $13.1 \%$ of the success attributed to the projects (Figure 1); however, by the end of the semester that proportion had increased to $27.4 \%$. Likewise, the minimum and maximum figures had changed from $10 \%$ and $25 \%$ to $20 \%$ and $40 \%$ respectively. Nevertheless, the average end of semester percentage is still significantly lower than the percentage quoted by the industry, as reflected in various surveys. For example, Goleman [30] claimed that compared to technical skills, the non-technical skills contribute more to the success or failure of an employee. Wade and Parent [31] supported these claims since they found that organizational skills are perceived as being the most important skills among analysts. This difference between the market requirements and the students' perception, as revealed in the questionnaire, can also be explained by the fact that although our program is about Management Information Systems — which leads to a variety of entry computing level jobs — most of our students regard their future employment as being mainly in software development. Taking into account their future planned jobs, the difference in their perception can only be explained by the workshop structure that emphasized the importance of soft skills. 


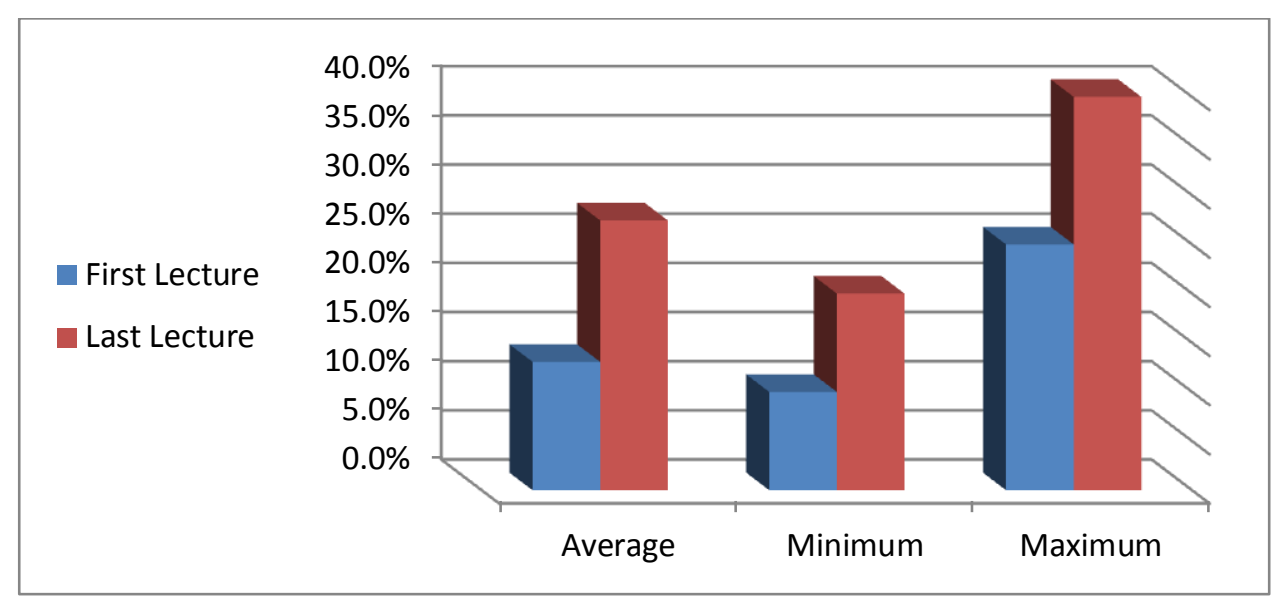

Figure 1. Student perceptions regarding non-technical skills (average, minimum, maximum)

Communication skills that correspond to the competencies outlined in the IS 2010 Model Curriculum [18] were enforced through a set of different activities:

Listening — through the various team activities, during the other teams' presentations, and in the requirements elicitation simulation.

Observing - through all the activities in the team, evaluating the other teams' papers, and incorporating the feedback received from peers and the instructor.

Interviewing - during the requirements elicitation interview simulation and the user presentation.

Writing skills — through the four documents each team had to compile, as well as through the four feedback documents.

Using virtual collaboration tools - through the tools used for the teamwork, rather than face to face meetings.

Giving effective presentations - through the team presentation in class, in which all team members had to participate.

Negotiation - through the activities carried out in the team, in which a commonly agreed solution had to be defined. In addition, there were some negotiations between the teams themselves regarding the feedback given.

Analytical thinking — which was exercised through the solution developed for the virtual customer, since the story was very general.

Critical thinking - exercised during the evaluation of each of the four documents, as well as during the presentation.

Innovation and creativity - enhanced through the process of finding the right solution to the user's problems, as well as applying some of the ideas presented in other teams documents.

Risk analysis - exercised during the planning stages of the solution, as well as for each document compiled and evaluated. A risk assessment of each team's presentation was carried out as part of grading the solution.

Ability to work independently — exercised throughout the whole workshop. Although most deliverables were derived from team activities, the actual tasks were performed individually by the team members, based on the agreed solution. All these specific tasks were later integrated into a coherent document.

In general, the workshop's structure, which employed Team Based Peer Review (TBPR), enhanced the students' critical thinking capabilities as well as their required soft skills [32]. Working effectively as a team member is a vital skill for information systems graduates and is one of the objectives of this study. To participate in TBPR, each team member must have good communication skills, including the ability to give and receive constructive criticism. The review process, like the document compilation process, started with individual reviews followed by a collaborative team meeting in which members had to reach a consensus and an agreed solution. Reviewing the documents proved to be very important. The process of reviewing documents prepared by different teams exposed the students to possible new solutions, and it helped them acquire new ideas and knowledge. This was evident in later stages of the workshop when two teams asked whether they could change their design, based on ideas they learned during the evaluation.

An additional indication of importance of soft skills in the learning process can be found in the students' reflections (as part of their personal reports). Some common reflections relating to the workshop include the following:

"I personally learned many things about the process, especially from what my team members did and the fact that it influences our collective grade. I still believe that technical capabilities are most important; however, they are not sufficient."

"Teamwork, both doing the assignments and evaluating other group work, is very important. We had 
cases in which the amount of coordination between the team members was not sufficient, and it was noticed in the resulting documents submitted and unfortunately affected our solution and the grade we received. We planned a good system, unfortunately due to insufficient communication it is not what the customer needs..."

"Although we worked already as a team, even so, in the beginning we had some team problems, maybe due to the workshops, intense assignments; but by the end of the workshop it was much better."

"I feel that the workshop provided me with a real life microcosm that allowed me to understand how real software development departments work. Finally, I understood the importance of the soft skills we discussed in the first lecture."

"In this workshop, we finally understood the importance of working as a team. Sometimes the task required mutual contribution in order to succeed. Technical capabilities are the most important ones, for example when considering future expected salary, however, without communication skills teamwork is impossible and the task will fail meeting its objectives."

These reflections provide insight into the students' understanding of how working in teams helped them improve their critical thinking in relation to both preparing their assignments and evaluating their peers' assignments. The students also realized that some basic preparations (or soft skills) are needed before a successful engagement in team-based activities. Future versions of the workshop will maintain the same structure, and it is hoped more students can be persuaded of the importance of soft skills for their future success.

\section{REFERENCES}

[1] S. Gillard, Soft Skills and Technical Expertise of Effective Project Managers. Issues in Informing Science and Information Technology, 6, 725. 2009 Retrieved from http://iisit.org/Vol6/IISITv6p723729Gillard599.pdf

[2] O. Hazzan, and J. Kramer, Abstraction in Computer Science \& Software Engineering: A pedagogical perspective. System Design Frontier Exclusive Frontier Coverage on System Designs, 4(1), 6-14 $2007 . \quad$ Retrieved from http://edu.technion.ac.il/Faculty/OritH/HomePage/Fr ontierColumns/OritHazzan_SystemDesigFrontier_C olumn5.pdf

[3] B. Sampson, Get with the project. Professional Engineering, 20(12), 41-42. 2007

[4] P. G. W. Keen, Information systems and organizational change. Communications of the ACM, 24(1), 24-33, 1981

[5] M. J. Earl, B. Edwards and D. F. Feeny, Configuring the IS Function in Complex Organizations. In Earl, M. J. (Ed.) Information Management: The
Organizational Dimension (pp. 201-230). Oxford. University Press, 1996.

[6] E. Trauth, D. Farwell and D. Lee, The IS Expectation Gap: Industry Expectations Versus Academic Preparation. MIS Quarterly, 17(3), 293-303, 1993

[7] D. Lee, E. Trauth and D. Farwell, Critical Skills and Knowledge Requirements of IS Professionals: A Joint Academic/Industry Investigation. MIS Quarterly, 19(3), 313-340, 1995

[8] T. Richards, R. Yellen, L. Kappelman and S. Guynes, Information Systems Manager's Perceptions of IS Job Skills. Journal of Computer Information Systems, 38(3) 53-57, 1998

[9] C. R. Woratschek and T. L. Lenox, Information Systems Entry-level Job Skills: A Survey of Employers. In The Proceedings of the Information Systems Education Conference 2002, 19. San Antonio.

[10]D. Young, The Relative Importance of Technical and Interpersonal Skills for New Information Systems Personnel. Journal of Computer Information Systems, 36(4), 66-71, 1996

[11]D. Zielinski, Soft skills, hard truths: How the projectmanagement discipline is rediscovering the power and importance of old-fashioned people skills. Training Magazine, July 2005

[12] A. Sukhoo, A. Barnard, M. M, Eloff, J. A. van der Poll and M. Motah, Skills in Software Project Management. Issues in Informing Science and Information Technology, 2, 691-704, 2005.

[13]R. Bancino and C. Zevalkink, Soft skills: The new curriculum for hard-core technical professionals. Techniques, 82(5), 20-22, 2007.

[14]J. L. Bailey and G. Stefanizk, Preparing the information technology workforce for the new millennium, ACM SIGCPR Computer Personnel, 20(4), 4-15, 2002.

[15]C. L. Noll and M. Wilkins, Critical skills of IS professionals: A model for curriculum development. Journal of Information Technology Education, 1(3), 143-154, 2002.

[16]T. Stader, State Farm Insurance Information Systems Student Recruiter, Interview, Northwestern State University, September 24, 2004.

[17]J. Russell and B. Russell, A Proposed Teaching Model for a Capstone Class in the IS Curriculum. Issues in Information Systems, VII(1), 249, 2006.

[18]H. Topi, J. S. Valacich, R. T. Wright, K. Kaiser, J. F. Nunamaker, J. C. Sipior and G. de Vreede, IS 2010: Curriculum Guidelines for Undergraduate Degree Programs in Information Systems. Communications of the AIS, 26(18), 2010. 
[19] J. Gorgone, G. B. Davis, J. S. Valacich, H. Topi, D. L. Feinstein and H. E. Longenecker, IS 2002 Model Curriculum and Guidelines for Undergraduate Degree Programs in Information Systems. The Communications of the Association for Information Systems, 11, article 1, 2003.

[20]D. L. Folse, H. E. Longenecker and R. J. Daigle, Influence of Covey Habit Training on Teams. In The Proceedings of ISECON 2003, v 20 (San Diego): $\$ 2233$. ISSN: 1542-7382. (Also appears in Information Systems Education Journal, 1(54).)

[21] M. L. Frandsen and L. K. Rhodes, Local IndustryStudent Team Collaboration on IT Projects: Experiences with a Multi-Semester Experiential Learning Course Sequence. In the Proceedings of ISECON 2002, v 19 (San Antonio): §343b. ISSN: 1542-7382.

[22]W. N. Owen, An Information Technology Capstone Course: An Assessment Implementation. In The Proceedings of ISECON 2001, v 18 (Cincinnati): $\S 34 \mathrm{c}$.

[23] J. Russell, B. Russell and W. Tastle, Teaching Soft Skills in a System Development Capstone Course. Information Systems Education Journal, 3(19), 2005.

[24]L. A. Schatzberg. Capstone Introductory IS Course: Strengthening Coverage of IS2002.1 and Disentangling it from IS2002.p0. In The Proceedings of ISECON 2003, v 20 (San Diego): §2421. ISSN: 1542-7382. (Also appears in Information Systems Education Journal, 1(1). ISSN: 1545-679X.)

[25]A. Roan and G. Whitehouse. Women, information technology and waves of optimism: Australian evidence on mixed-skill jobs. Work and Employment, 22(1), 21-33, 2007.

[26] J. Flynn, T. R. Valikoski and J. Grau, Listening in the Business Context: Reviewing the State of Research. The International Journal of Listening, 22, 141-151, 2008.

[27]A. Fisher, The Trouble with MBAs. Fortune International, 155(7), 33-34, 2007.

[28] J. Cappel. Entry-level IS job skills: A survey of employers. Journal of Computer Information Systems, 42(2), 76-82, 2002.

[29]A. Faheem. Software Requirements Engineer: An Empirical Study about Non-Technical Skills. Journal of Software, 7(2), 389-397, 2010.

[30]D. Goleman, Emotional intelligence. NY: Bantam Books, 1995.

[31] M. R. Wade and M. Parent, Relationships between job skills and performance: A study of webmasters. Journal of Management Information Systems, 18(3), 71-96, 2001.

[32] S. Covey, Unstoppable teams. Executive Excellence, 13(7), 7-8, 1996.
Dr. Aharon Yadin is a Senior Lecturer at the Max Stern Yezreel Valley College (YVC), Management Information Systems Department. Aharon's primary teaching areas are related to computer architectures and programming and business/management information systems issues. Prior to entering the academic world, Aharon worked in the High Tech industry. He has over 30 years of IT experience including: management, system performance analysis and enhancement, computer center and IS management, wireless networks and communication technologies and document management.

Aharon has published over one hundred papers, assays and scientific and technological reports (many in Hebrew), he is the author of 12 Hebrew instructional books. In addition, he consults the European Commission on software related projects and technologies. 